\title{
Patient characteristics and trends in nontraumatic dental condition visits to emergency departments in the United States
}

This article was published in the following Dove Press journal:

Clinical, Cosmetic and Investigational Dentistry

12 January 2012

Number of times this article has been viewed

\author{
Christopher Okunseri' \\ Elaye Okunseri' \\ Joshua M Thorpe 2 \\ Qun Xiang ${ }^{3}$ \\ Aniko Szabo 3 \\ 'Department of Clinical Services, \\ Marquette University School of \\ Dentistry, Milwaukee, WI, ${ }^{2}$ Division \\ of Social and Administrative Sciences, \\ University of Wisconsin, Madison \\ School of Pharmacy, Madison WI, \\ ${ }^{3}$ Division of Biostatistics, Department \\ of Population Health, Medical College \\ of Wisconsin, Milwaukee, WI, USA
}

Correspondence: Christopher Okunser Department of Clinical Services Room 356, Marquette University School of Dentistry, PO Box 188I Milwaukee,

Wisconsin 5320I-I88I, USA

$\mathrm{Tel}+\mathrm{I} 4 \mathrm{I} 42886524$

Fax + I 4|4 2883586

Email christopher.okunseri@marquette.edu
Objective: We examined trends and patient characteristics for non-traumatic dental condition (NTDC) visits to emergency departments (EDs), and compared them to other ED visit types, specifically non-dental ambulatory care sensitive conditions (non-dental ACSCs) and non-ambulatory care sensitive conditions (non-ACSCs) in the United States.

Methods: We analyzed data from the National Hospital Ambulatory Medical Care survey (NHAMCS) for 1997 to 2007. We performed descriptive statistics and used a multivariate multinomial logistic regression to examine the odds of one of the three visit types occurring at an ED. All analyses were adjusted for the survey design.

Results: NTDC visits accounted for $1.4 \%$ of all ED visits with a $4 \%$ annual rate of increase (from $1.0 \%$ in 1997 to $1.7 \%$ in 2007). Self-pay patients (32\%) and Medicaid enrollees (27\%) were over-represented among NTDC visits compared to non-dental ACSC and non-ACSC visits $(P<0.0001)$. Females consistently accounted for over $50 \%$ of all types of ED visits examined. Compared to whites, Hispanics had significantly lower odds of an NDTC visit versus other visit types $(P<0.0001)$. Blacks had significantly lower odds of making NDTC visits when compared to non-dental ACSC visits only $(P<0.0001)$. Compared to private insurance enrollees, Medicaid and self-pay patients had 2-3 times the odds of making NTDC visits compared to other visit types.

Conclusion: Nationally, NTDC visits to emergency departments increased over time. Medicaid and self-pay patients had significantly higher odds of making NDTC visits.

Keywords: emergency service, dental disease, adults, dental utilization

\section{Introduction}

The use of emergency departments for non-urgent or preventable medical conditions is a growing public health concern for policymakers, health advocates, and providers across the United States. Nationally, emergency department visits increased by approximately $26 \%$ and $38 \%$ at different times from 1994 to $2007 .{ }^{1-4}$ Depending on either delay of care, duration of symptoms prior to ED presentation and other medical criteria, the majority of studies report an increase of between $20 \%$ and $35 \%$ for non-urgent conditions..$^{5-8}$ Nonetheless, there is some doubt about the reliability of these estimates because of inconsistencies in the description of non-urgent visits to emergency departments by different investigators. ${ }^{8}$ Despite this, these trends are of concern given the current economic climate, the ongoing debate on the Health Care Reform Act and the fact that emergency departments are gradually becoming overstretched and are approaching capacity. 
Few studies have attempted to document information on the use of emergency departments for non-traumatic dental condition visits, and most of these used non-probability samples with small sample sizes drawn from urban, local, and state hospitals. ${ }^{9-13}$ One exception was a rather dated study by Lewis et al, which reported that dental-related ED visits were more likely to occur among Medicaid enrollees or uninsured patients. ${ }^{14}$ Recently, Okunseri et al analyzed Medicaid claims data from the state of Wisconsin and found that adults, Native Americans, and enrollees residing in entire dental health professional shortage areas were significantly more likely to make NTDC visits to EDs and physicians' offices (POs). ${ }^{15}$ Information on national trends for NTDC visits to EDs continues to be scarce and the subject receives limited attention.

Ambulatory care sensitive conditions (ACSCs) are conditions for which timely and effective outpatient care could prevent or minimize the need for hospital-based services, that is conditions for which appropriate and timely primary medical and/or dental intervention could prevent or reduce the odds of emergency department visits for different population groups (see Appendix). NTDCs are a part of ambulatory care sensitive conditions (see Appendix). Therefore, we hypothesized that NTDC visits would exhibit different epidemiological patterns when compared to other ED visit types or would be similar to other ACSC conditions. Our study focused on expanding our understanding of the different $\mathrm{ED}$ visit patterns: non-traumatic dental condition, non-dental ACSC and non-ambulatory care sensitive condition (non-ACSC) visits. The study used nationally representative data available for 1997 to 2007 to examine trends and patient characteristics for NTDC visits and compared them to non-dental ACSC and non-ACSC visits to emergency departments in the United States. The study provides robust and generalizable information on trends and patient characteristics that are important for program planning and policy development.

\section{Methods}

\section{Data source}

We analyzed data from the National Hospital Ambulatory Medical Care Survey (NHAMCS) for 1997-2007. The NHAMCS was initiated in 1992 to gather, analyze, and disseminate information about health care provided by hospital emergency departments and outpatient departments. NHAMCS is part of the ambulatory component of the National Health Care Surveys, a family of surveys that measures health care utilization across various types of providers. The NHAMCS is designed to provide information about the health problems of ambulatory patients and the treatment given to them in hospital emergency and outpatient departments. NHAMCS data is collected in accordance with the privacy guidelines of the Health Insurance Portability and Accountability Act (HIPAA). ${ }^{3}$

\section{Statistical analyses}

We used the primary diagnosis code for each ED visit to classify it as an NTDC, non-dental ACSC visit, or non-ACSC visit. We performed descriptive statistics and used multivariate multinomial logistic regression to examine the odds of an ED visit belonging to one of the three considered visit types. All analyses were adjusted for the survey design. Age was categorized into 6 groups, with cut-offs chosen to approximate the lower and upper tenth and twenty-fifth quartiles, and the median in the entire population. Based on findings from the descriptive statistics, calendar year was treated as a linear continuous predictor in the multivariate analyses. All statistical analyses were performed using $\mathrm{SAS}^{\odot}$ software version 9.2 (SAS Institute Inc, Cary, NC), with the primary model fitted using Proc Surveylogistic. Sample estimates were weighted to provide national estimates, and standard errors were adjusted to reflect the complex sampling scheme of NHAMCS. An alpha level of 0.05 was used throughout to denote statistical significance. The study was approved by the Marquette University Institutional Review Board.

\section{Results}

From 1997-2007, non-traumatic dental condition visits accounted for $1.4 \%$, non-dental ACSC visits, $17.8 \%$, and non-ACSC visits $81 \%$ of all ED visits in the United States (Table 1). The distribution of the different types of ED visits across the years is shown in Figure 1. The proportion of non-ACSC and non-dental ACSC visits to EDs was almost uniform over time, albeit with a gradual increase, unlike the distribution of NTDC visits which increased sharply over time. Table 2 shows demographic characteristics for the three types of visits to emergency departments (nonACSC, non-dental ACSC and NTDC) analyzed in this study. Females consistently accounted for slightly over $50 \%$ of NTDC, non-ACSC, and non-dental ACSC visits. The distribution of NTDC visits was significantly different from that of non-ACSC and non-dental ACSC visits by payer type $(P<0.0001)$. Self-pay patients were over-represented among NTDC visits compared to non-dental ACSC and non-ACSC visits (32\% versus $14 \%$ and $16 \%$ ). Most of the non-ACSC and non-dental ACSC visits were by private insurance patients $(38 \%, 33 \%)$. The gender distribution of 
Table I Counts and distribution of different emergency department visits: 1997-2007

\begin{tabular}{llll}
\hline $\begin{array}{l}\text { Emergency } \\
\text { department } \\
\text { visit type }\end{array}$ & $\begin{array}{l}\text { Frequency } \\
\text { in NHAMCS }\end{array}$ & $\begin{array}{l}\text { Estimated } \\
\text { frequency } \\
\text { in population }\end{array}$ & $\begin{array}{l}\text { Percent } \\
\text { of visits (SE) }\end{array}$ \\
\hline Non-ACSC & 281,435 & $969,453,023$ & $80.8(0.2)$ \\
Non-dental ACSC & 60,617 & $213,350,353$ & $17.8(0.2)$ \\
NTDC & 4,726 & $16,379,580$ & $1.4(0.1)$ \\
\hline
\end{tabular}

Abbreviations: Non-ACSC, non-ambulatory care sensitive conditions; non-denta ACSC, non-dental ambulatory care sensitive conditions; NTDC, non-traumatic dental condition; NHAMCS, National Hospital Ambulatory Medical Care Survey; $\mathrm{SE}$, standard error.

NTDC visits was very similar to that of non-ACSC visits $(P=0.3)$, but significantly different from non-dental ACSC visits, which had a 2.4 percentage point higher representation of females $(P=0.01)$.

The age distribution of NTDC visits was significantly different from that of both non-ACSC visits and nondental ACSC visits $(P<0.0001)$. Adults $(19-52$ years $)$ and especially younger adults (19-33 years) were substantially overrepresented, with $79 \%$ and $48 \%$ of NTDC visits respectively. In contrast, for non-ACSC visits, adults were $52 \%$ and younger adults $25 \%$. For non-dental ACSC visits, adults were $38 \%$ and younger adults $19 \%$. Correspondingly, older patients were underrepresented among NTDC visits, with fewer than $2 \%$ of such visits occurring among patients aged 73 years or older, compared to about $11 \%$ in the other categories. The racial/ethnic distribution of NTDC visits compared to non-ACSC visits and non-dental ACSC visits was significantly different $(P<0.0001)$. Whites accounted for over $50 \%$ of all three types of ED visits followed by nonHispanic blacks with $17 \%$ to $21 \%$. Hispanics consistently

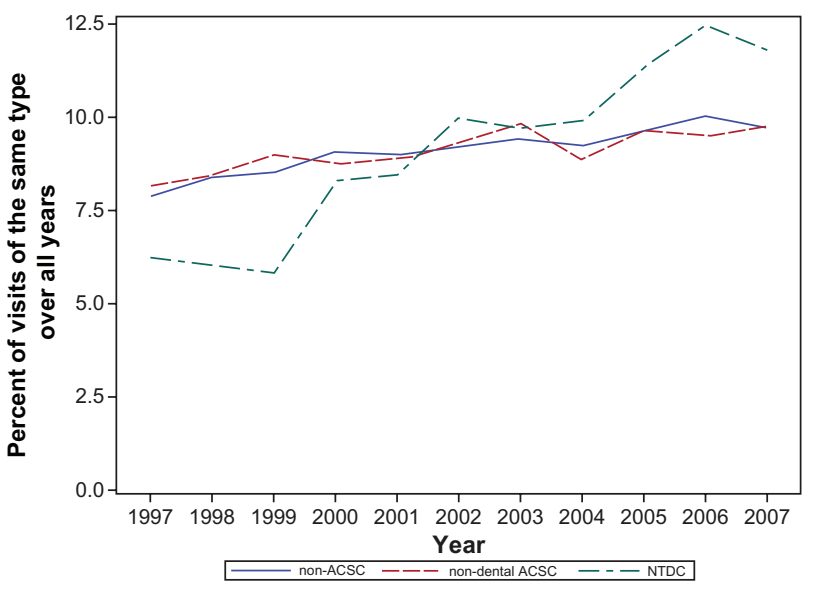

Figure I Frequency polygon showing the distribution of the different ED visit types: 1997-2007.

Abbreviations: Non-ACSC, non-ambulatory care sensitive condition; Non-dental ACSC, non-dental ambulatory care sensitive condition; NTDC, non-traumatic dental condition. accounted for over $10 \%$ of non-dental ACSC and non-ACSC visits, and slightly less than $10 \%$ of NTDC visits.

Table 3 shows the multivariate multinomial logistic regression analysis of the effect of the predictors on the odds of making an NTDC visit compared to non-dental ACSC and non-ACSC visits. In general, the findings are consistent with the univariate descriptive statistics. Compared to private insurance patients, self-pay and Medicaid enrollees had significantly higher odds of having had an NTDC visit compared to non-ACSC and non-dental ACSC visits. Compared to 19-33 year olds, all other age groups had significantly lower odds of having had an NTDC visit compared to non-ACSC and non-dental ACSC visits. Compared to non-Hispanic whites, Hispanics had 57\%-65\% lower odds of making an NDTC visit than a non-ACSC or non-dental ACSC visit $(P<0.0001)$, and Blacks had significantly lower odds for NTDC visits only when compared to non-dental ACSC visits. Females had significantly lower odds $(\mathrm{OR}=0.84)$ of making NTDC visits to EDs compared to non-dental ACSC visits, but the difference for non-ACSC visits $(\mathrm{OR}=0.98)$ was not significant.

\section{Discussion}

Despite the growing number of articles from state Medicaid databases and non-probability samples published on the use of EDs for NTDC visits, little is known about national trends and patient characteristics of ED use for NTDC visits. We found a substantial increase in NTDC and ACSC visits to emergency departments from 1997 to 2007 in the United States. NTDC visits to emergency departments increased by $54 \%$ at an annual rate of $4 \%$ during the study period. This increase is troubling given that the total of all ED visits increased by about $23 \%$ and the overall population increased by $12.5 \%$ during the same study period. ${ }^{4}$ In addition, the NTDC visits population is in many aspects more similar to the non-ACSC visits population than the non-dental ACSC population. This somewhat contradicts what we expected a priori and thus highlights that there are different underlying processes and attributes for making these different visits. Furthermore, because ACSCs can be used to evaluate access to care, our findings indicate that there is a lingering problem of inadequate access to dental care for many Americans, ${ }^{16}$ and that the use of EDs for NTDC visits still remains a public policy concern due to the associated cost implications. It is also important to note that treatments provided at emergency departments for NTDCs and ACSCs are for the most part temporary care and do not offer the opportunity for care continuity. 
Table 2 Demographic characteristics for the three types of emergency department visits (non-ACSC, non-dental ACSC and NTDC) for children and adults, 1997-2007

\begin{tabular}{|c|c|c|c|c|c|}
\hline Variable & $\begin{array}{l}\text { Non-ACSC visits } \\
\% \text { (SE) }\end{array}$ & $\begin{array}{l}\text { Non-dental } \\
\text { ACSC visits } \\
\% \text { (SE) }\end{array}$ & $\begin{array}{l}\text { NTDC visits } \\
\% \text { (SE) }\end{array}$ & $\begin{array}{l}\text { Non-ACSC } \\
\text { versus NTDC } \\
\text { P-value } \\
\end{array}$ & $\begin{array}{l}\text { Non-dental ACSC } \\
\text { versus NTDC } \\
\text { P-value } \\
\end{array}$ \\
\hline Payer type & & & & $<0.0001$ & $<0.0001$ \\
\hline Private insurance & $37.8(0.5)$ & $33.3(0.6)$ & $25.4(0.9)$ & - & - \\
\hline Medicaid & I9.I (0.4) & $27.6(0.5)$ & $26.8(0.9)$ & & \\
\hline Medicare & $14.6(0.2)$ & $17.0(0.4)$ & $5.8(0.5)$ & - & - \\
\hline Self-pay & $15.7(0.3)$ & $13.8(0.3)$ & $32.2(1.1)$ & - & - \\
\hline Unknown & $9.3(0.4)$ & $5.5(0.3)$ & $6.8(0.7)$ & - & - \\
\hline Other & $3.6(0.2)$ & $2.8(0.2)$ & $3.0(0.4)$ & - & - \\
\hline Gender & & & & 0.3126 & 0.0163 \\
\hline Female & $52.9(0.2)$ & $56.3(0.3)$ & $53.9(1)$ & - & - \\
\hline Male & $47.1(0.2)$ & $43.7(0.3)$ & $46.1(1)$ & - & - \\
\hline Age group & & & & $<0.0001$ & $<0.0001$ \\
\hline $0-4$ years & $9.1(0.2)$ & $2 \mathrm{I} . \mathrm{I}(0.5)$ & $4.9(0.4)$ & & \\
\hline $5-18$ years & $15.2(0.2)$ & $15.6(0.2)$ & $9.1(0.6)$ & - & - \\
\hline $19-33$ years & $25.0(0.2)$ & $19.2(0.3)$ & $47.7(1.2)$ & - & - \\
\hline $34-52$ years & $26.7(0.2)$ & $18.4(0.3)$ & $31.0(0.9)$ & - & - \\
\hline $53-72$ years & $14.2(0.1)$ & $13.8(0.3)$ & $5.6(0.4)$ & - & - \\
\hline Over 73 years & $9.9(0.2)$ & $11.9(0.3)$ & $1.8(0.3)$ & - & - \\
\hline Race/ethnicity & & & & $<0.0001$ & $<0.0001$ \\
\hline Non-hispanic white & $56.4(1)$ & $5 \mathrm{I} .8(\mathrm{I} . \mathrm{I})$ & $55.7(1.6)$ & - & - \\
\hline Non-hispanic black & I7.4 (0.7) & $21.1(0.9)$ & $21.2(1.1)$ & - & - \\
\hline Hispanic & $10.8(0.6)$ & I $3.0(0.8)$ & $8.8(0.7)$ & & \\
\hline Other & $2.3(0.2)$ & $2.1(0.2)$ & $2.0(0.3)$ & - & - \\
\hline Unknown ethnicity & I3.I (0.8) & $11.9(0.8)$ & $12.2(1.1)$ & - & - \\
\hline
\end{tabular}

Abbreviations: Non-ACSC, non-ambulatory care sensitive conditions; non-dental ACSC, non-dental ambulatory care sensitive conditions; NTDC, non-traumatic dental condition; SE, standard error.

Compared to 19-33 year olds, all other age groups in the study had significantly lower odds of making any of the ED visits described. This finding is consistent with prior studies in medicine and dentistry, which document that people older than 18 years were significantly more likely to use EDs for NTDC visits. ${ }^{15,17,18}$ Tang et al reported that adults 18-64 years old had significantly higher rates of making ED visits, while children less than 18 years old and adults 65 years and older did not show significant differences in their visit rates. ${ }^{4}$ While our study used different age cut-offs, we found that persons aged 53-72 years and those 73 years old and older had significantly lower odds of making NTDC visits, compared to non-ACSC and non-dental ACSC visits. Furthermore, Okunseri et al reported that young to middle-aged adults aged 19 to 42 years were most likely to be frequent users of EDs and POs for NTDCs. ${ }^{19}$ These results clearly suggest that the use of EDs for NTDC visits in the United Sates is peculiar to young and middle-aged adults and could be directly linked to inadequate access to dental care. It is therefore necessary that the development of strategies to address ED use for NTDC visits should focus more on health care system factors that are related to adults.
Dental care financing and other demographic factors influence an individual's ability to decide on whether and where to receive dental care in the United States. We found that persons identified as self-pay and those enrolled in Medicaid had significantly higher adjusted odds of making an NTDC visit, compared to private insurance patients for both non-ACSC and non-dental ACSC visits. Interestingly, the self-pay and Medicaid groups constituted slightly over $50 \%$ of the population presenting to EDs for NTDC visits and should most likely benefit from safety net dental programs. That being said, Bailit et al have reported that safety net dental programs have a limited capacity relative to the size of the underserved population, ${ }^{20}$ even with the passing of legislation such as the Health Care Safety Net Amendments of 2002. ${ }^{21}$ Additionally, findings on Medicaid enrollees are consistent with prior studies that have documented their use of EDs as a primary source of care and the many barriers they face in accessing dental care in private offices., ${ }^{4,22,23}$ These include the misdistribution of dentists, low Medicaid reimbursement and the severe shortage of minority dentists who are reported to be more likely to accept new Medicaid patients. ${ }^{24-27}$ 
Table 3 Multivariate multinomial logistic regression analysis: the effect of the predictor on the odds of an NTDC visit compared to non-ACSC and non-dental ACSC visits

\begin{tabular}{|c|c|c|c|c|}
\hline \multirow[t]{2}{*}{ Predictor } & \multicolumn{4}{|c|}{ Adjusted odds ratio (OR) and $95 \%$ confidence interval } \\
\hline & NTDC versus non-ACSC & $P$-value & NTDC versus non-dental ACSC & $P$-value \\
\hline \multicolumn{5}{|l|}{ Payer type } \\
\hline Private insurance & 1.00 & & 1.00 & \\
\hline Medicaid & $2.22(2.00-2.48)$ & $<0.0001$ & $1.67(1.49-1.86)$ & $<0.0001$ \\
\hline Medicare & $1.34(1.07-1.67)$ & 0.0117 & $1.04(0.83-1.30)$ & 0.7445 \\
\hline Self-pay & 2.5 I (2.28-2.77) & $<0.000$ I & $2.38(2.14-2.65)$ & $<0.000$ I \\
\hline Unknown & $1.00(0.83-1.21)$ & 0.9950 & I.4I (I.I7-I.70) & 0.0004 \\
\hline Other & $1.19(0.92-1.53)$ & 0.1908 & $1.33(1.03-1.70)$ & 0.0271 \\
\hline \multicolumn{5}{|l|}{ Gender } \\
\hline Female & $0.98(0.91-1.06)$ & 0.6369 & $0.84(0.77-0.91)$ & $<0.0001$ \\
\hline Male & 1.00 & & 1.00 & \\
\hline \multicolumn{5}{|l|}{ Age group (year) } \\
\hline $0-4$ & $0.28(0.23-0.35)$ & $<0.0001$ & $0.10(0.08-0.12)$ & $<0.000$ I \\
\hline $5-18$ & $0.33(0.29-0.39)$ & $<0.0001$ & $0.26(0.22-0.30)$ & $<0.0001$ \\
\hline $19-33$ & 1.00 & & 1.00 & \\
\hline $34-52$ & $0.65(0.59-0.73)$ & $<0.0001$ & $0.73(0.65-0.8 \mathrm{I})$ & $<0.000$ I \\
\hline $53-72$ & $0.24(0.20-0.28)$ & $<0.0001$ & $0.20(0.16-0.23)$ & $<0.0001$ \\
\hline 73 and over & $0.11(0.08-0.16)$ & $<0.000$ I & $0.08(0.06-0.11)$ & $<0.0001$ \\
\hline \multicolumn{5}{|l|}{ Race/ethnicity } \\
\hline Non-hispanic white & 1.00 & & 1.00 & \\
\hline Non-hispanic black & $0.99(0.89-1.11)$ & 0.9195 & $0.78(0.70-0.88)$ & $<0.000$ I \\
\hline Hispanic & $0.67(0.58-0.77)$ & $<0.000$ I & $0.57(0.49-0.66)$ & $<0.000$ I \\
\hline Other & $0.86(0.65-1.14)$ & 0.3017 & $0.89(0.66-1.20)$ & 0.4504 \\
\hline Unknown ethnicity & $1.02(0.88-1.18)$ & 0.8145 & I.0I (0.87-I.I7) & 0.8976 \\
\hline Year & $1.05(1.04-1.07)$ & $<0.0001$ & $1.06(1.04-1.08)$ & $<0.000$ I \\
\hline
\end{tabular}

Abbreviations: Non-ACSC, non-ambulatory care sensitive conditions; Non-dental ACSC, non-dental ambulatory care sensitive conditions; NTDC, non-traumatic dental condition.

Tang et al documented that blacks had nearly twice as high ED visit rates compared to non-Hispanic whites and Hispanics. ${ }^{4}$ In our study, Hispanics and blacks had significantly lower odds for NTDC visits compared to nondental ACSC visits to EDs after adjustment for available covariates. Cunningham et al reported that people who had public insurance coverage, belonged to the black race, and were low income earners were more likely to use EDs for non-urgent medical care. ${ }^{7}$ Our findings are in contrast with literature documentation stating that blacks are more likely to use EDs for primary care because they do not have a usual source of care. ${ }^{28}$ When compared with non-ACSC visits, Hispanics had significantly lower odds of NDTC visits despite published reports on the disproportionate burden of dental diseases in racial and ethnic minority groups. One possible explanation for the differences seen among racial and ethnic minorities could be related to cultural norms/attitudes about oral hygiene or dental care-seeking behavior.

There are potential limitations to our study that should be mentioned. First, patient-specific identifiers were not provided in the database, thus making it impossible to determine whether an individual had more than one visit for any of the ED visit types examined during the data collection period. Secondly, we recognize that all data were collected and coded by ED staff and could be subject to coding errors. Third, the data documented discharge diagnosis and did not capture the individual perspectives of the ED users or their concepts of emergency conditions requiring care at the ED.

\section{Conclusion}

NTDC visits increased over time and Medicaid and self-pay patients have significantly higher odds of making NDTC visits in the United States. Inappropriate and continuous use of emergency departments for ACSC and NTDC visits are troubling and may contribute to overcrowding, increased care costs and longer wait times for patients with urgent medical and dental conditions. A reduction in all identified ED visit types would require different intervention strategies given the mix of the population involved in making different types of ED visits. Regardless of one's perspective, NTDC visits are best addressed in a dental office setting due to the availability of definitive care and the likelihood of continuity of care. 


\section{Acknowledgments}

This study was supported by grant \#1R15DE021196-01 from the National Institute of Dental and Craniofacial Research.

\section{Disclosure}

The authors report no conflicts of interest in this work.

\section{References}

1. Kellermann AL. Crisis in the emergency department. $N$ Engl J Med. 2006;355(13):1300-1303.

2. Nawar EW, Niska RW, Xu J. National hospital ambulatory medical care survey: 2005 emergency department summary. Advance data from vital and health statistics; no 386. Hyattsville, MD: national center for health statistics; 2007. Available from: http://www.cdc.gov/nchs/data/ ad/ad386.pdf.

3. Pitts SR, Niska RW, Xu J, Burt CW. National hospital ambulatory medical care survey: 2006 emergency department summary. National health statistics reports; no 7. Hyattsville, MD: national center for health statistics. 2008. Available from: http://www.cdc.gov/nchs/data/nhsr/ nhsr007.pdf.

4. Tang N, Stein J, Hsia RY, Maselli JH, Gonzales R. Trends and characteristics of US emergency department visits, 1997-2007. JAMA. 2010;304(6):664-670.

5. Isaacman DJ, Davis HW. Pediatric emergency medicine: state of the art. Pediatrics. 1993;91(3):587-590.

6. Liu T, Sayre MR, Carleton SC. Emergency medical care: types, trends, and factors related to nonurgent visits. Acad Emerg Med. 1999;6(11): $1147-1152$.

7. Cunningham PJ, Clancy CM, Cohen JW, Wilets M. The use of hospital emergency departments for nonurgent health problems: a national perspective. Med Care Res Rev. 1995;52(4):453-474.

8. Durand AC, Gentile S, Devictor B, et al. ED patients: how nonurgent are they? Systematic review of the emergency medicine literature. Am J Emerg Med. 2011;29(3):333-345.

9. Waldrop RD, Ho B, Reed S. Increasing frequency of dental patients in the urban ED. Am J Emerg Med. 2000;18(6):687-689.

10. Agostini FG, Flaitz CM, Hicks MJ. Dental emergencies in a universitybased pediatric dentistry postgraduate outpatient clinic: A retrospective study. ASDC J Dent Child. 2001;68(5-6):316-321, 300-301.

11. Rowley ST, Sheller B, Williams BJ, Mancl L. Utilization of a hospital for treatment of pediatric dental emergencies. Pediatric Dent. 2006; 28(1):10-17.

12. Ladrillo TE, Hobdell MH, Caviness AC. Increasing prevalence of emergency department visits for pediatric dental care, 1997-2001. J Am Dent Assoc. 2006;137(3):379-385.

13. Graham DB, Webb MD, Seale NS. Pediatric emergency room visits for nontraumatic dental disease. Pediatr Dent. 2000;22(2):134-140.

14. Lewis C, Lynch H, Johnston B. Dental complaints in emergency departments: A national perspective. Ann Emerg Med. 2003;42(1): 93-99.
15. Okunseri C, Pajewski N, Brousseau D, Tomany-Korman S, Snyder A, Flores G. Non-traumatic dental condition visits to emergency departments and physicians' offices. J Am Dent Assoc. 2008;139(12): $1657-1666$.

16. McCall N, Harlow J, Dayhoff D. Rates of hospitalization for ambulatory care sensitive conditions in the Medicare+Choice population. Health Care Financing Rev. 2001;22:127-145.

17. McCaig LF, Burt CW. National hospital ambulatory medical care survey: 2003 emergency department summary-advance data from vital health and statistics, no. 358. hyattsville, MD: national center for health statistics; 2005. Available from: http://www.cdc.gov/nchs/data/ ad/ad358.pdf.

18. Hunt KA, Weber EJ, Showstack JA, Colby DC, Callaham ML. Characteristics of frequent users of emergency departments. Ann Emerg Med. 2006;48(1):1-8.

19. Okunseri C, Pajewski N, Scott J, et al. Frequent users of emergency departments and physicians' offices for treatment of nontraumatic dental conditions among Wisconsin Medicaid enrollees. J Am Dent Assoc. 2011;142(5):540-550.

20. Bailit H, Beazoglou T, Demby N, McFarland J, Robinson P, Weaver R. Dental safety net: current capacity and potential for expansion. $J \mathrm{Am}$ Dent Assoc. 2006;137(6):807-815.

21. Health Care Safety Net Amendments of 2002 [P.L. 107-251], 116 STAT. 1621-1665. 42 USC 201. October 26, 2002. Available from: http://history.nih.gov/research/downloads/PL107-251.pdf.

22. Falik M, Needleman J, Wells BL, Korb J. Ambulatory care sensitive hospitalizations and emergency visits: Experiences of Medicaid patients using federally qualified health centers. Med Care. 2001;39(6): 551-561.

23. Backus L, Osmond D, Grumbach K, Vranizan K, Phuong L, Bindman AB. Specialists' and primary care physicians' participation in Medicaid managed care. J Gen Intern Med. 2001;16(12):815-821.

24. Mertz EA, Grumbach K. Identifying communities with dentist supply in California. J Public Health Dent. 2001;61(3):172-177.

25. Okunseri C, Bajorunaite R, Abena A, Self K, Iacopino AM, Flores G. Racial/ethnic disparities in the acceptance of Medicaid patients in dental practices. J Public Health Dent. 2008;68(3):149-153.

26. General Accounting Office. Oral health: Dental disease is a chronic problem among low-income populations. United States General Accounting Office (GAO), Report to Congressional Requester. Washington, DC: GAO/HEHS-00-72, Apr 2000:44. Available from: http://www.gao.gov/new.items/he00072.pdf. Accessed April 30, 2011.

27. Lewin ME, Altman S, editors. America's Health Care Safety Net: Intact but Endangered. Washington, DC, Institute of Medicine: National Academy Press; 2000.

28. National center for health statistics Health, United States, 2006 with chartbook on trends in the health of Americans. Hyattesville, MD: 2006. Available from: http://www.cdc.gov/nchs/data/hus/hus06.pdf. Accessed February 14, 2008 


\section{Appendix \\ Description of non-traumatic dental conditions (NTDC)}

Patients with NTDC visits were identified by physician discharge diagnosis codes assigned based on the International Classification of Diseases 9th Revision-Clinical Modification (ICD-9-CM). The ICD-9-CM discharge diagnostic codes defined in our study as NTDC visits are as follows: 520.0 521.9 (disorders of tooth development and eruption, diseases of dental hard tissues of teeth); 522.0-522.9 (diseases of pulp and periapical tissues); 523.0-523.9 (gingival and periodontal diseases); 524.0-524.9 (dentofacial anomalies, including malocclusion); 525.0 (exfoliation of teeth due to systemic causes); 525.2 (atrophy of edentulous alveolar ridge), 525.3, (retained dental root);525.4 (complete edentulism) 525.5 (partial edentulism); 525.6 (unsatisfactory restoration of tooth); 525.9 (unspecified disorder of the teeth and supporting structures); 526.0-526.9 (diseases of the jaw); 527.0-527.9 (diseases of the salivary glands); 528.0-528.9 (diseases of the oral soft tissues, excluding lesions specific for gingival and tongue and excluding 528.3 which includes Ludwig's angina); 529.0-529.9 (diseases and other conditions of the tongue); and 873.63 (internal structures of mouth, without broken teeth). These selected ICD-9-CM codes for NTDC visits are identical to those used in other published studies analyzing dental visits to emergency departments. ${ }^{15}$

\section{Description of ambulatory medical care sensitive conditions (ACSC)}

Ambulatory care sensitive conditions are conditions for which timely and effective outpatient care could prevent or minimize the need for hospital-based services. They include such conditions as complications from diabetes, perforated appendicitis, chronic obstructive pulmonary disease, hypertension, congestive heart failure, dehydration, urinary infections, dental problems, and adult asthma. ACSCs were defined following the definitions of the Agency for Healthcare Research and Quality (AHRQ), as implemented in the Prevention Quality Indicators which form part of the AHRQ Quality Indicators program. ACSCs were subdivided into dental ACSCs (defined as ACSC that are also NTDCs), and all other conditions.
Clinical, Cosmetic and Investigational Dentistry

\section{Publish your work in this journal}

Clinical, Cosmetic and Investigational Dentistry is an international, peer-reviewed, open access, online journal focusing on the latest clinical and experimental research in dentistry with specific emphasis on cosmetic interventions. Innovative developments in dental materials, techniques and devices that improve outcomes and patient satisfac-

\section{Dovepress}

tion and preference will be highlighted. The manuscript management system is completely online and includes a very quick and fair peerreview system, which is all easy to use. Visit http://www.dovepress. com/testimonials.php to read real quotes from published authors. 